\title{
Novel dynamin 2 mutations in adult T-cell acute lymphoblastic leukemia
}

\author{
ZHENG GE ${ }^{1-3^{*}}$, MIN LI $^{2 *}$, GANG ZHAO ${ }^{1 *}$, LICHAN XIAO $^{2}$, YAN GU $^{2}$, XILIAN ZHOU $^{2}$, \\ MICHAEL D. YU ${ }^{4}$, JIANYONG LI ${ }^{2,5}$, SINISA DOVAT ${ }^{3}$ and CHUNHUA SONG ${ }^{3}$
}

\begin{abstract}
${ }^{1}$ Department of Hematology, Key Department of Jiangsu Medicine, Zhongda Hospital, Southeast University Medical School, Nanjing, Jiangsu 210009; ${ }^{2}$ Department of Hematology, The First Affiliated Hospital of Nanjing Medical University, Jiangsu Province Hospital, Nanjing, Jiangsu 210029, P.R. China; ${ }^{3}$ Department of Pediatrics, Pennsylvania State University College of Medicine, Hershey, PA 17033; ${ }^{4}$ Department of Internal Medicine, Sidney Kimmel Medical College at Thomas Jefferson University, Philadelphia, PA 19107, USA; ${ }^{5}$ Collaborative Innovation Center for Cancer Personalized Medicine, Nanjing, Jiangsu 210029, P.R. China
\end{abstract}

Received February 10, 2016; Accepted July 20, 2016

DOI: $10.3892 / \mathrm{ol} .2016 .4993$

\begin{abstract}
Genetic mutations on signaling pathways are found in patients with T-cell acute lymphoblastic leukemia (T-ALL) and act as markers of high-risk leukemia. Mutations in dynamin 2 (DNM2) have been reported in T-ALL, particularly in early T-cell precursor-ALL. In the present study, DNM2 mutations were screened by sequencing DNM2 exons obtained by polymerase chain reaction amplification and gel purification in adult T-ALL patients. A total of 4 novel DNM2 mutations were identified in adult T-ALL patients, with a mutation rate of $9.5 \%$, and the DNM2 mutations were found to co-exist with NOTCH1 and PHD finger protein 6, and were also associated with high-risk leukemia. A high rate of silent mutation was also found in the patients, but no significant association was found between the silent mutations and patients' clinical features. The present findings suggested the DNM2 mutations may be involved in the oncogenesis of T-ALL.
\end{abstract}

Correspondence to: Dr Zheng Ge, Department of Hematology, Key Department of Jiangsu Medicine, Zhongda Hospital, Southeast University Medical School, 300 Guangzhou Street, Nanjing, Jiangsu 210009, P.R. China

E-mail: janege879@hotmail.com

Dr Chunhua Song, Department of Pediatrics, Pennsylvania State University College of Medicine, 500 University Drive, Hershey, PA 17033, USA

E-mail: csong@hmc.psu.edu

*Contributed equally

Key words: dynamin 2, adult, T-cell acute lymphoblastic leukemia

\section{Introduction}

Acute lymphoblastic leukemia (ALL) is the most common malignancy in B cells, immature $\mathrm{T}$ lymphocytes or lymphoid progenitors (1). T-cell acute lymphoblastic leukemia (T-ALL) accounts for $\sim 15$ and $25 \%$ of ALL in pediatric and adult patients, respectively (2). Patients with T-ALL usually have high white blood cell (WBC) counts and may present with organomegaly, particularly mediastinal enlargement and central nervous system (CNS) involvement (3). The biological knowledge of T-ALL is limited. Previously, T-ALL was classified into five subgroups (pro-T, pre-T, cortical, mature T-ALL and ETP) based on the results of fluorescent in situ hybridization (FISH), molecular biology and gene expression profiling (4). With exome-sequencing and whole genome sequencing, genetic mutations on genes including NOTCH1, F-box and WD repeat domain containing 7 (FBXW7), Ras, PHD finger protein 6 (PHF6) and Janus kinase 1 (JAK1) have been found to be high-risk markers in patients with T-ALL $(3,5,6)$.

The GTPase dynamin 2 (DNM2) is essential for intracellular vesicle formation and trafficking, cytokinesis and receptor endocytosis. DNM2 contains five domains, as follows: GTPase domain; intermediate domain (MD); pleckstrin homology domain (PH); GTPase effector domain (GED); and proline-arginine-rich domain (PRD). High DNM2 expression is observed in prostate cancer and associated with cancer progression (7). DNM2 potentiates invasive migration of pancreatic tumor cells (8). Inhibition of DNM2 induced cell death in 11 cancer cell lines (9). Previously, DNM2 genetic mutations were identified in a subtype of T-ALL, termed early T-cell precursor (ETP) ALL, which accounts for up to $15 \%$ of T-ALL and is associated with a high risk of treatment failure $(6,10)$. However, to the best of our knowledge, no studies have investigated DNM2 genetic mutations in adult ALL. The present study sequenced the exons of DNM2 genes in 42 patients with T-ALL, and the clinical features in the patients with DNM2 mutations were analyzed. 


\section{Materials and methods}

Patients and samples. Bone marrow (BM) samples from 42 patients with newly diagnosed T-ALL, consisting of 31 male patients with a median age of 26 years (range, 16-62 years) and 11 female patients with a median age of 29 years (range, 19-60 years), were collected between July 2010 and December 2014 at the First Affiliated Hospital of Nanjing Medical University (Nanjing, Jiangsu, China). The diagnosis of ALL was made according to the morphological, immunophenotypical, cytogenetic and molecular criteria of the 2008 World Health Organization Diagnosis and Classification of ALL (11). All patients provided written informed consent, in accordance with the Declaration of Helsinki, prior to enrollment in the study. The present study was approved by the Institutional Review Board of Nanjing Medical University.

Mutational analysis of DNM2. Mutational analysis of DNM2 exons 2-22 was performed. Genomic DNA was isolated using a Wizard ${ }^{\circledR}$ Genomic DNA Purification kit (Promega Corporation, Madison, WI, USA) according to the manufacturer's protocol. DNA fragments spanning the aforementioned DNM2 exons were amplified by PCR using AmpliTaq Gold kit (Applied Biosystems; Thermo Fisher Scientific, Inc., Waltham, MA, USA) and exon-specific primers. The primers for PCR amplification of DNM2 exons were as follows: exon 2 forward, TGCAAGACAGAG TTGCTCCAC and reverse, TGTGTAAGTGTTCACTGA GCCG; exon 3 forward, CCAGCCTGGGTCATTACTTTC and reverse, ACACAGGCTCACCCATAGCAC; exon 4 forward, GTGGTTCAGGCAGAGTGTCAG and reverse, GACTTGGAACCAAGGATGCTG; exon 5 forward, CTG TGAGATCAGGGCTGTGAC and reverse, GGAGAAGCA ATGACTTCCAGG; exon 6 forward, TACTTGAATCTT GCCCATCCC and reverse, CTGAAACAAGTGCCAGTG AGG; exon 7 forward, ATAGTGGCACCCTGGTGTTG and reverse, GTGGACGAGTGATGAGTGGTG; exon 8 forward, GTAAACCCTGGCTTGACTTGG and reverse, CTTGAG ACCTTATTGCCTGGG; exon 9 forward, GTGTGAGCC ACTGTATCTGGC and reverse, GGACTCAGAGGTGTG GGTGAC; exon 10 forward, CAACCTTCATTCCTTGTT GGG and reverse, CTGGGAGCCTGATACCAAACC; exon 12 forward, TCTTCTGCTCTTAGCTCCCAG and reverse, TGTCAGCATGCACAGAACAGT; exon 13 forward, TCTGTTGCCTATGAGGGTGTG and AATCCCAACTCA GTCACCTCC; exon 14 forward, CTACCTGTGGCTGCT CACTTG and reverse, TAGAGAGAGCAGATGGCCTGG; exon 16 forward, GGGCTGGAGGTGTCTCTATTG and reverse, GCAGTGACTGAGTTCTGCCC; exon 17 forward, TCATATACAGCAGCGACCAGC and reverse, GTGCTC AGTGCTCAGTGAAGG; exon 18 forward, CTAGAGCCC ATTCCTCTCGG and reverse, CATGATTTCAGAGAC TCCTGGC; exon 19 forward, TAGGGCAGATGGTTTCCA GAG and reverse, CTCCTTAGCTCGTGATCCGC; exon 20 forward, CCCGCCCTGTGAGAGATG and reverse, AGG ACCCTGCAGGACACAC; exon 21 forward, CACCTCAGG TTCTGGCAGC and reverse, ACTGGGAGGAAGTGAGAC AGG; and exon 22 forward, GAGTTGATGCCTAGGTTT GGC and reverse GAGCCTGGTCCCAGCATAG. Exons in NOTCH1, FBXW7, PHF6, phosphatase and tensin homolog
(PTEN), JAK1 and interleukin (IL)-7R were also amplified as previously reported (11-15).

The PCR products of the DNM2 gene exons 2-22, NOTCH1 gene exons 26-28 and 34, FBXW7 gene exons 5-12, PHF6 gene exons 2-10, PTEN gene exons 1-9, JAK1 gene exons 13, 14, 16, 18 and 19 and IL-7R exons 2-8 were purified in $2 \%$ agarose gel and cloned into the vector by The Beijing Genomics Institute (BGI; Beijing, China) and sequenced by BGI or Shanghai Bojin Medical Instrument Co., Ltd. (Shanghai, China).

Cytogenetic and molecular analyses. Conventional cytogenetic analysis was performed at the time of diagnosis, using unstimulated short-term cultures, according to the recommendations of the International System for Human Cytogenetic Nomenclature (16). For each sample, at least 20 BM metaphase cells were analyzed.

Immunophenotypical analyses were performed by flow cytometry on fresh BM samples as described previously $(17,18)$. The following antibody conjugates were used: anti-cluster of differentiation (CD)3-fluorescein isothiocyanate (FITC; catalog no., 555339), anti-CD2-allophycocyanin (APC; catalog no.,560642), anti-CD5-phycoerythrin (PE; catalog no.,555353), anti-CD7-brilliant violet 421 (BV421; catalog no., 562635), anti-CD19-FITC (catalog no., 555412), anti-CD20-APC (catalog no., 559776), anti-CD10-BV421 (catalog no., 562902), anti-CD34-PE (catalog no., 555822) and anti-CD33-BV605 (catalog no., 740400). All the antibodies were mouse antihuman and purchased from BD Biosciences (San Jose, CA, USA) and used for cell staining according to the manufacturer's protocol. FITC, PE, BV605 and BV421-conjugated antibodies were diluted 1:5; APC-conjugated antibodies were diluted 1:20. The stained cells were analyzed on a FACScalibur flow cytometer (BD Biosciences), which was equipped with red and blue lasers. Routine machine calibration was performed daily according to the standard operating procedures of our laboratory. Fluorescence compensation calibration was run at least once a week using standard fluorescence beads (Calibrite beads; BD Biosciences). Data analysis was performed using BD CellQuest ${ }^{\mathrm{TM}}$ Pro software version 6.0 (BD Biosciences), and lymphocytes were delineated using forward scatter/side scatter dot plots. Cell-surface antigens were defined as present when the fluorescence intensity of $\geq 20 \%$ of cells exceeded the fluorescence of the negative control.

Statistical analysis. For qualitative parameters, overall group differences were analyzed using a $\chi^{2}$ test. All statistical analyses were performed using SPSS version 17.0 (SPSS, Inc., Chicago, IL, USA). P $<0.05$ was considered to indicate statistical significance.

\section{Results}

Mutational analysis of DNM2. DNM2 mutations were identified in 4 out of 42 T-ALL patients, resulting in a mutation incidence of $9.5 \%$. The 4 mutations were the point mutations c. $1081 \mathrm{C}>\mathrm{T}, \mathrm{c} .1453 \mathrm{~T}>\mathrm{C}, \mathrm{c} .1609 \mathrm{G}>\mathrm{A}$ and c. $1801 \mathrm{C}>\mathrm{T}$, which were located in exons $8,13,16$ and 18 , respectively. In the 4 mutations, 1 mutation was a nonsense mutation and 3 mutations were missense mutations. All 4 mutations led to amino acid changes (R361X, Y485H, G537S and R601W). The R361X 
Table I. Co-existence of DNM2, NOTCH1 and PHF6 mutations in adult patients with T-cell acute lymphoblastic leukemia.

\begin{tabular}{|c|c|c|c|c|c|c|}
\hline \multirow[b]{2}{*}{ Patient ID } & \multicolumn{2}{|c|}{ DNM2 } & \multicolumn{2}{|c|}{ NOTCH1 } & \multicolumn{2}{|c|}{ PHF6 } \\
\hline & Mutation & Location & Mutation & Location & Mutation & Location \\
\hline Mu1\# & $\begin{array}{c}\text { c.1081C }>\text { T, } \\
\text { p.R361X }\end{array}$ & exon 8 & $\begin{array}{l}\text { c.4732_4734delGTG, } \\
\text { p.V1578delV, } \\
\text { c.5094C>T, p.D1698D }\end{array}$ & $\begin{array}{l}\text { exon } 26 \\
\text { exon } 27\end{array}$ & $\begin{array}{c}\text { c. } 820 \mathrm{C}>\mathrm{T} \\
\text { p.R274X }\end{array}$ & exon 8 \\
\hline $\mathrm{Mu} 2 \#$ & $\begin{array}{c}\text { c. } 1453 \mathrm{~T}>\mathrm{C} \\
\text { p.Y485H }\end{array}$ & exon 13 & $\begin{array}{l}\text { c. } 5033 \mathrm{~T}>\mathrm{C}, \mathrm{p} . \mathrm{L} 1678 \mathrm{P} \\
\text { c. } 7400 \mathrm{C}>\mathrm{A}, \mathrm{p} . \mathrm{S} 2467^{*}\end{array}$ & $\begin{array}{l}\text { exon } 27 \\
\text { exon } 34\end{array}$ & $\begin{array}{c}\text { c. } 346 \mathrm{C}>\mathrm{T} \\
\text { p.R116X }\end{array}$ & exon 4 \\
\hline Mu3\# & $\begin{array}{l}\text { c. } 1609 \mathrm{G}>\mathrm{A}, \\
\text { p.G537S }\end{array}$ & exon 16 & c. $4721 \mathrm{~T}>\mathrm{C}, \mathrm{p} . \mathrm{L} 1574 \mathrm{P}$ & exon 26 & $\begin{array}{c}\text { c. } 385 \mathrm{C}>\mathrm{T}, \\
\text { p.R } 129 \mathrm{X}\end{array}$ & exon 5 \\
\hline Mu4\# & $\begin{array}{l}\text { c. } 1801 \mathrm{C}>\mathrm{T}, \\
\text { p.R601W }\end{array}$ & exon 18 & $\begin{array}{l}\text { c.7427G }>\text { C, p.V7427L } \\
\text { c.7171delinsTTTT, } \\
\text { p.Q2391fs } 3\end{array}$ & exon 34 & & \\
\hline
\end{tabular}

DNM2, dynamin 2; PHF6, PHD finger protein 6.

and $\mathrm{Y} 485 \mathrm{H}$ mutations are located within the DNM2 MD; G537S and R601W mutations are located within the DNM2 PH domain (Fig. 1).

DNM2 mutation in combination with NOTCH1 and PHF6 mutation. The present study found that in these 4 patients, DNM2 mutations co-existed with NOTCH1 mutations. In 3 of the 4 patients, the DNM2 mutation co-existed with two NOTCH1 mutations (point mutations and/or indel mutations) located in NOTCH1 exons 26, 27 and 34. In addition, 3 of the 4 patients with DNM2 mutations had PHF6 mutations located in PHF6 exons 4, 5 and 8 (Table I).

Clinical characteristics of the patients with DNM2 mutations. The clinical characteristics of the patients with DNM2 mutations are listed on Table II. No significant differences in clinical characteristics were observed between the patients with DNM2 mutations and those without mutations in terms of age $(\mathrm{P}=0.094)$, sex $(\mathrm{P}=1.000), \mathrm{T} / \mathrm{B}$ subtype diagnosis $(\mathrm{P}=1.000)$, initial WBC $(\mathrm{P}=0.453)$, HGB $(\mathrm{P}=0.602)$, platelets $(\mathrm{P}=0.950)$, lactate dehydrogenase $(\mathrm{P}=0.317)$, blasts in bone marrow $(\mathrm{P}=0.939)$, blasts in peripheral blood $(\mathrm{P}=0.900)$, immune phenotype $\mathrm{CD}^{+} 4^{+}(\mathrm{P}=0.098), \mathrm{CD}^{+} 0^{+}(\mathrm{P}=0.866)$, $\mathrm{CD}^{+} 9^{+}(\mathrm{P}=1.000), \mathrm{CD} 20^{+}(\mathrm{P}=1.000), \mathrm{CD}^{+}{ }^{+}(\mathrm{P}=1.000), \mathrm{CD}^{+}$ $(\mathrm{P}=0.525), \mathrm{CD}^{+}(\mathrm{P}=0.535), \mathrm{CD}^{+}(\mathrm{P}=0.777)$ and $\mathrm{CD}^{+}$ $(\mathrm{P}=1.000)$, frequency of extramedullary infiltration on liver $(\mathrm{P}=0.888)$, spleen $(\mathrm{P}=0.204)$ and lymph nodes $(\mathrm{P}=1.000)$, and days for complete remission $(\mathrm{P}=0.234)$. However, it was found that 1 patient experienced relapse, 1 patient had a high WBC count, and 2 patients had complex karyotypes and lymph node infiltration. Notably, the time taken to reach complete remission was $>4$ weeks in all 4 patients. These data suggest that the patients with DNM2 mutation exhibit high-risk leukemia and possess a poor prognosis.

DNM2 synonymous amino acid mutations. DNM2 synonymous amino acid mutations were identified in exon 4 (1/42 patients; $2.38 \%$ ), exon 6 (1/42 patients; $2.38 \%$ ), exon 22 (1/42 patients; $2.38 \%$ ), and exon 20 (34/42 patients; 80.95\%) in the T-ALL patients. There were two synonymous amino acid mutations, Ala713Ala and Asp720Asp, in exon 20, and the former mutation was found in 31 patients (31/42 patients; $73.81 \%)$ and the latter in 3 patients (3/42 patients; 7.14\%). The coexistence of the two mutations was identified in 1 case (1/42 patients; $2.38 \%)$ (Table III). The clinical features of the patients with DNM2 synonymous amino acid mutations were also observed, but these synonymous amino acid mutations were not significantly associated with any clinical features observed (data not shown).

\section{Discussion}

The DNM2 protein is involved in a wide range of cellular functions, including phagocytosis, phagosome formation of actin and microtubule interactions, cytokinesis, cell migration and regulation of apoptosis (19). It has been reported that DNM2 gene mutation is an important factor for patients with autosomal dominant centronuclear myopathy (20) and Alzheimer's disease $(21,22)$.

Recurrent DNM2 mutations have also been identified in patients with ETP-ALL by whole-exome sequencing $(6,10,23)$. These mutations include: E78fs in the Ras-like GTPase domain; L3354P, R364C, K382E, T404N and E468* in the dynamin MD domain; S528fs, E544fs and K557_K558>K in the PH domain; S698L in the GTPase effector domain; and K770*,P791T, L789fs and $\mathrm{I} 805 \mathrm{fs}$ in the C-terminus. In addition, it has been shown that certain mutations appear in patients that experience relapse with induction failure. The present study identified 4 novel DNM2 mutations in 42 adult T-ALL patients, with a mutation rate of $9.5 \%$. These mutations also mainly appear in the dynamin central region (MD domain), $\mathrm{PH}$ domain and GTPase effector domains. It was also found that the patients with DNM2 mutations were more likely to demonstrate high-risk factors, such as a high WBC count, complex karyotype, lymph node infiltration and difficulty achieving complete remission. These data indicated that patients with T-ALL with DNM2 mutations have a poor outcome.

Patient Mul\# was diagnosed with a type of hypoproliferative leukemia termed 'hypocellular leukemia', with less tolerance to 
Table II. Clinical characteristics of T-ALL patients with DNM2 mutations.

\begin{tabular}{|c|c|c|c|c|c|}
\hline \multirow[b]{2}{*}{ Characteristics } & \multicolumn{4}{|c|}{ Mutation } & \multirow{2}{*}{$\begin{array}{l}\text { No mutation, } \\
\text { median (range) }\end{array}$} \\
\hline & Mu1\# & $\mathrm{Mu} 2 \#$ & Mu3\# & Mu4\# & \\
\hline Age, years & 27 & 26 & 26 & 14 & $30.0(14.0-70.0)$ \\
\hline Gender & $\mathrm{F}$ & M & M & M & $\mathrm{F} / \mathrm{M}$ \\
\hline Diagnosis & T-ALL & T-ALL & T-ALL & T-ALL & T-ALL \\
\hline DNM2 mutations & $\mathrm{R} 361 \mathrm{X}$ & $\mathrm{Y} 485 \mathrm{H}$ & G537S & $\mathrm{R} 601 \mathrm{~W}$ & No \\
\hline $\mathrm{WBC}, \mathrm{nx} 10^{9} / 1$ & 2.9 & 106.7 & 28.9 & 54.4 & $44.2(1.0-546.0)$ \\
\hline HGB, g/l & 117 & 124 & 92 & 114 & $115.5(56.0-171.0)$ \\
\hline PLT, $\mathrm{nx} 10^{9} / 1$ & 85 & 76 & 46 & 56 & $58.5(17.0-267.0)$ \\
\hline LDH, U/1 & 934 & 731 & 861 & 588 & $1,144.0(131.0-8601.0)$ \\
\hline Blasts in bone marrow, $\%$ & 56.4 & 95.6 & 90.2 & 72.4 & $76.0(20.0-100.0)$ \\
\hline Blasts in peripheral blood, \% & 6.0 & 68.0 & 88.0 & 89.0 & $64.0(0.0-100.0)$ \\
\hline \multicolumn{6}{|l|}{ Immune phenotype ${ }^{a}$} \\
\hline $\mathrm{CD}_{3} 4^{+}$ & Negative & Negative & Negative & Negative & \\
\hline $\mathrm{CD}^{+} 0^{+}$ & Negative & Negative & Positive & Negative & \\
\hline $\mathrm{CD}_{19}{ }^{+}$ & Negative & Negative & Negative & Negative & \\
\hline $\mathrm{CD} 20^{+}$ & Negative & Negative & Negative & Negative & \\
\hline $\mathrm{CD}_{3} 3^{+}$ & Negative & Positive & Negative & Negative & \\
\hline $\mathrm{CD} 2^{+}$ & Negative & Positive & Negative & Positive & \\
\hline $\mathrm{CD}^{+}$ & Negative & Positive & Positive & Negative & \\
\hline $\mathrm{CD}^{+}$ & Positive & Positive & Negative & Positive & \\
\hline $\mathrm{CD}^{+}$ & Positive & Positive & Positive & Positive & \\
\hline \multicolumn{6}{|l|}{ Extramedullary infiltration } \\
\hline Liver & No & No & No & No & \\
\hline Spleen & No & No & No & No & \\
\hline Lymph node metastasis & No & No & No & Yes & \\
\hline Karyotype & $46, \mathrm{XX}[20]$ & $\begin{array}{c}46, \mathrm{XY}, \operatorname{der}(1), \\
9 \mathrm{p}-, 14 \mathrm{q}+[3] / 47, \mathrm{XY} \\
\mathrm{t}(6 ; 11)(\mathrm{p} 10 ; \mathrm{p} 10) \\
+? 8,9 \mathrm{p}-[1] / 46, \mathrm{XY}[6]\end{array}$ & $46, X Y[20]$ & $\begin{array}{c}46, \mathrm{XY}, 11 \mathrm{q} \\
+[3][\mathrm{inc}] / 46, \mathrm{XY}[1] \\
2013.1 .7: 47-48, \\
\mathrm{XY},-1,2 \mathrm{q}-,-4,4 \mathrm{q}- \\
-5,+8,9 \mathrm{p}-, \text { der }(9) \\
+11,11 \mathrm{q}-{ }^{*} 2,12 \mathrm{q}+ \\
16 \mathrm{q}+, 17 \mathrm{q}- \\
+2 \mathrm{mar}[7 \mathrm{cp}] / 46 \\
\text { XY[3] }\end{array}$ & \\
\hline Rearrangement & TCR/TCR & TCR/TCR & TCR/TCR & TCR/TCR & \\
\hline $\begin{array}{l}\text { Time to complete } \\
\text { remission, days }\end{array}$ & 61 & 43 & 60 & 65 & $28(9-169)$ \\
\hline
\end{tabular}

${ }^{a}$ Cell-surface antigens were defined as present when the fluorescence intensity of $\geq 20 \%$ of cells exceeded the fluorescence of the negative control. F, female; M, male; T-ALL, T-cell acute lymphoblastic leukemia; DNM2, dynamin 2; WBC, white blood cell; HGB, hemoglobin; PLT, platelet; LDH, lactate dehydrogenase; CD, cluster of differentiation; TCR, T cell receptor.

chemotherapy and poor clinical outcome compared to individual's with normal/increased WBC counts. Hypocelluar leukemia is most commonly observed in cases of acute myeloid leukemia, and certain cases are secondary leukemia resulting from myelodysplastic syndrome, indicating high-risk leukemia $(24,25)$. The mechanism of hypoproliferative leukemia is not fully understood. The present study identified that 5 immunotypes were present in patient Mu2\#, but only 2-3 immunotypes were present in the other 3 patients with detected mutations. Only CD33 was observed in patient Mu2\#, suggesting this immunotype may lead to a poorer outcome compared with those observed in the other 3 patients. In addition, the association of the mutations with survival of the patients requires clarification with more patients with the mutations in future. 


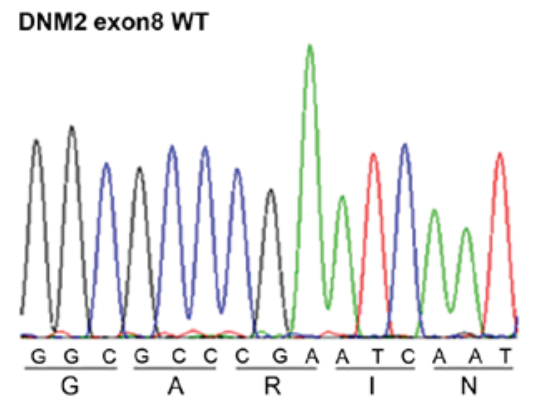

DNM2 exon13 WT
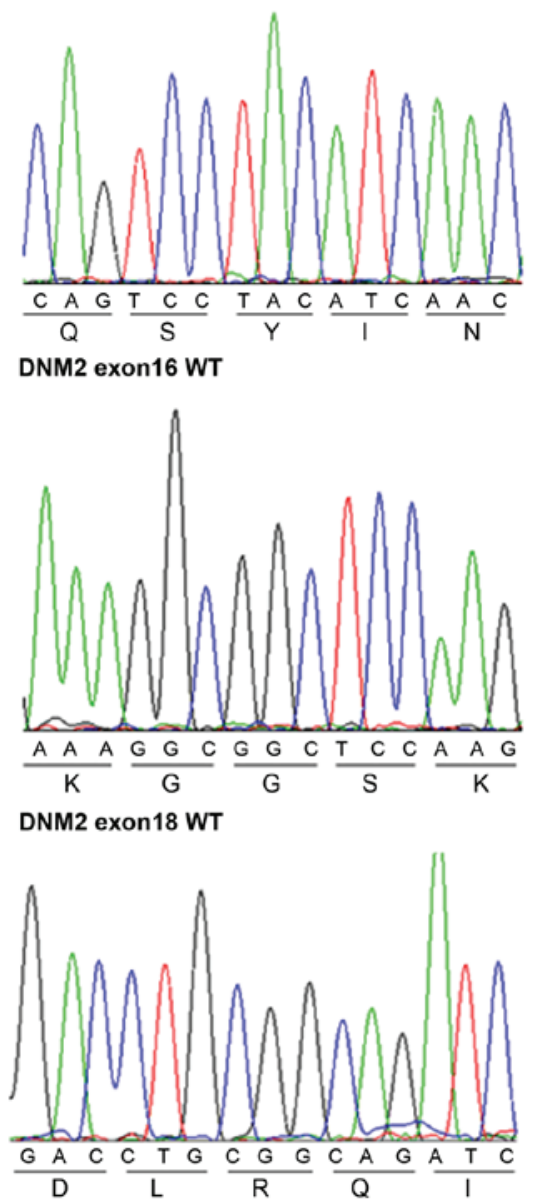

DNM2 exon8 nonsense mutation R361X

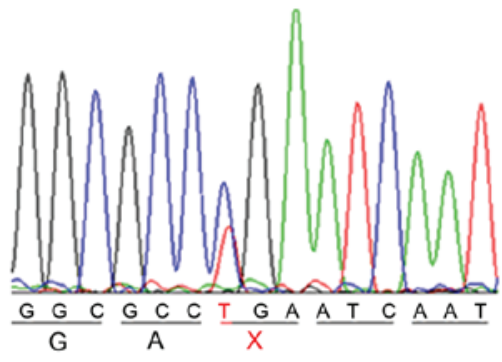

DNM2 exon13 Y485H
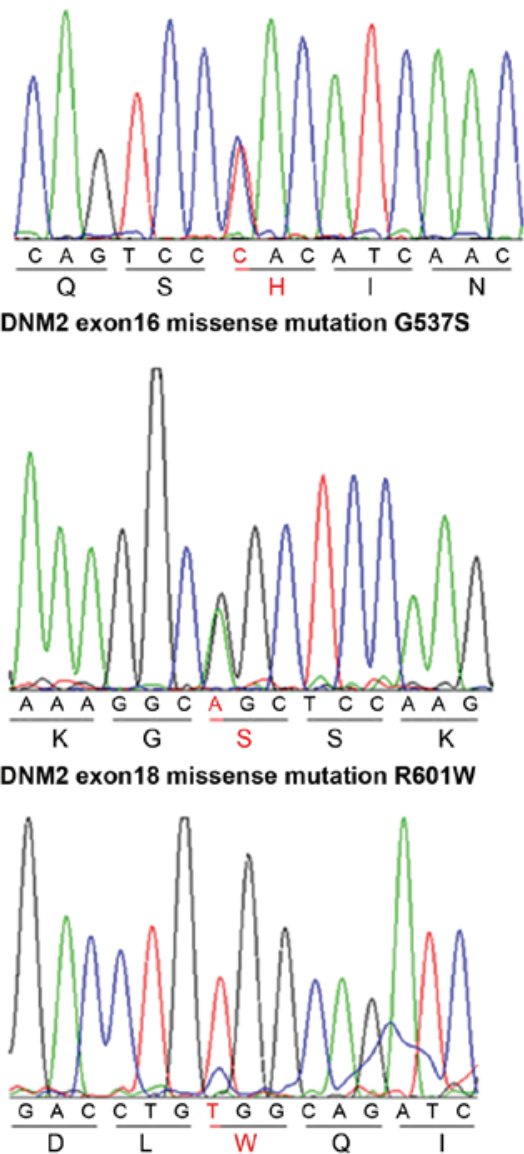

Figure 1. Representative DNA sequencing chromatograms of T-cell acute lymphoblastic leukemia genomic DNA samples showing mutations in exons of DNM2. DNM2, dynamin 2; WT, wild type.

Table III. Mutations of synonymous amino acids in exons of DNM2.

\begin{tabular}{rccc}
\hline Exon & Cases, $n$ & $\begin{array}{c}\text { Mutation, } \\
\text { nucleotide }\end{array}$ & $\begin{array}{c}\text { Mutation, } \\
\text { amino acid }\end{array}$ \\
\hline 4 & 1 & c.450A $>\mathrm{G}$ & p.P150P \\
6 & 1 & c.789G $>\mathrm{A}$ & p.P263P \\
20 & 31 & c.2139T $>\mathrm{C}$ & p.A713A \\
20 & 3 & c.2160C $>\mathrm{T}$ & p.D720D \\
20 & 1 & c.2139T $>\mathrm{C}^{+}$ & p.A713A \\
& & c.2160C $>\mathrm{T}$ & p.D720D \\
22 & 1 & c.2571G $>\mathrm{A}$ & p.R857R \\
\hline
\end{tabular}

DNM2, dynamin 2.
DNM2 can bind to membrane phospholipids through PH domains and the endogenous GED can activate GTPase activity. In addition, high DNM2 expression is associated with a poor prognosis and high rate of metastasis in patients with solid cancer. Inhibition of DNM2 induces the apoptosis of cancer cells (8-10). Therefore, the present authors hypothesize that the DNM2 mutations identified in the present study may be gain-of-function mutations. The effects of these newly-identified DNM2 mutations on the proliferation of leukemia cells in the current study may be examined in future studies.

Notably, a high rate of DNM2 synonymous amino acid mutations (also termed silent mutations) was identified in the patients. Silent mutations are the evolutionary substitution of one base for another in an exon of a gene coding for a protein, such that the produced amino acid sequence is not modified. However, 
mutations do not always result in silent mutations (26-28). The point mutation may affect transcription, splicing, mRNA transport and translation, any of which may alter the phenotype, rendering the synonymous mutation non-silent (26-28).

In the present study, DNM2 expression was not observed in the patients with DNM2 silent mutations, and no significant changes in DNM2 expression were found in the patients with silent mutations compared to patients without mutations. In addition, no significant association between the DNM2 silent mutations and any clinical features was observed. These data indicated that the sites with silent mutations may only be the hot spots and the nucleotides in these sites are easily changed, but the nucleotide changes may also be quickly corrected. The clinical relevance of DNM2 silent mutations requires additional clarification. It was hypothesized in the present study that silent mutations may affect DNM2 translation in patients (26-28).

In summary, the present study identified 4 novel DNM2 mutations in T-ALL and their associations with high-risk leukemia. The current findings suggest the DNM2 mutations may be involved in the oncogenesis of T-ALL.

\section{Acknowledgements}

This study was supported by the following organizations: The National Natural Science Foundation of China (grant nos. 81270613 and 30973376); Jiangsu Province Key Medical Talents (grant no. RC2011077); The Scientific Research Foundation for the Returned Overseas Chinese Scholars, State Education Ministry (39th); China Postdoctoral Science Foundation (grant no. 20090461134); Special Grade of the Financial Support from China Postdoctoral Science Foundation (grant no. 201003598); The Six Great Talent Peak Plan of Jiangsu (grant no. 2010-WS-024); The Scientific Research Foundation for the Returned Overseas Chinese Scholars, Nanjing Municipal Bureau of Personnel (2009); and Project of National Key Clinical Specialty, and Project funded by Jiangsu Provincial Special Program of Medical Science (grant no. BL2014086). The study was also supported partially by the Four Diamond Foundation of Pennsylvania State University.

\section{References}

1. Pui CH, Relling MV and Downing JR: Acute lymphoblastic leukemia. N Engl J Med 350: 1535-1548, 2004.

2. Mody R, Li S, Dover DC, Sallan S, Leisenring W, Oeffinger KC, Yasui Y, Robison LL and Neglia JP: Twenty-five-year follow-up among survivors of childhood acute lymphoblastic leukemia: A report from the childhood cancer survivor study. Blood 111: $5515-5523,2008$

3. Chiaretti S and Foà R: T-cell acute lymphoblastic leukemia. Haematologica 94: 160-162, 2009.

4. Ferrando AA, Neuberg DS, Staunton J, Loh ML, Huard C, RaimondiSC,Behm FG, PuiCH,Downing JR, Gilliland DG, et al: Gene expression signatures define novel oncogenic pathways in $\mathrm{T}$ cell acute lymphoblastic leukemia. Cancer Cell 1: 75-87, 2002.

5. Roberts KG and Mullighan CG: Genomics in acute lymphoblastic leukaemia: Insights and treatment implications. Nat Rev Clin Oncol 12: 344-357, 2015.

6. Neumann M, Vosberg S, Schlee C, Heesch S, Schwartz S, Gökbuget N, Hoelzer D, Graf A, Krebs S, Bartram I, et al: Mutational spectrum of adult T-ALL. Oncotarget 6: 2754-2766, 2015.

7. Xu B, Teng LH, Silva SD, Bijian K, Al Bashir S, Jie S, Dolph M, Alaoui-Jamali MA and Bismar TA: The significance of dynamin 2 expression for prostate cancer progression, prognostication, and therapeutic targeting. Cancer Med 3: 14-24, 2014.
8. Razidlo GL, Wang Y, Chen J, Krueger EW, Billadeau DD and McNiven MA: Dynamin 2 potentiates invasive migration of pancreatic tumor cells through stabilization of the Rac1 GEF Vav1. Dev Cell 24: 573-585, 2013.

9. Chircop M, Perera S, Mariana A, Lau H, Ma MP, Gilbert J, Jones NC, Gordon CP, Young KA, Morokoff A, et al: Inhibition of dynamin by dynole 34-2 induces cell death following cytokinesis failure in cancer cells. Mol Cancer Ther 10: 1553-1562, 2011.

10. Neumann M, Heesch S, Schlee C, Schwartz S, Gökbuget N, Hoelzer D, Konstandin NP, Ksienzyk B, Vosberg S, Graf A, et al: Whole-exome sequencing in adult ETP-ALL reveals a high rate of DNMT3A mutations. Blood 121: 4749-4752, 2013.

11. Guo X, Zhang R, Liu J, Li M, Song C, Dovat S, Li J and Ge Z: Characterization of LEF1 high expression and novel mutations in adult acute lymphoblastic leukemia. PLoS One 10: e0125429, 2015.

12. Parsons DW, Li M, Zhang X, Jones S, Leary RJ, Lin JC, Boca SM, Carter H, Samayoa J, Bettegowda C, et al: The genetic landscape of the childhood cancer medulloblastoma. Science 331: 435-439, 2011.

13. Lin ZK, Zhang R, Ge Z, Liu J, Guo X, Qiao C, Wu YJ, Qiu HR, Zhang JF and Li JY: Characteristics of NOTCH1 mutation in adult T-cell acute lymphoblastic leukemia. Zhongguo Shi Yan Xue Ye Xue Za Zhi 21: 1403-1408, 2013 (In Chinese).

14. Guo X, Zhang R, Ge Z, Xu JY, Li M, Qiao C, Qiu HR and Li JY: Mutations of FBXW7 in adult T-cell acute lymphocytic leukemia. Zhongguo Shi Yan Xue Ye Xue Za Zhi 23: 612-618, 2015 (In Chinese).

15. Wang Q, Qiu H, Jiang H, Wu L, Dong S, Pan J, Wang W, Ping N, Xia J, Sun A, et al: Mutations of PHF6 are associated with mutations of NOTCH1, JAK1 and rearrangement of SET-NUP214 in T-cell acute lymphoblastic leukemia. Haematologica 96: 1808-1814, 2011.

16. Shaffer LG, Slovak ML and Campbell LJ (eds): An International System for Human Cy togenetic Nomenclature. Recommendations of the International Standing Committee on Human Cytogenetic Nomenclature. Karger, Basel, Switzerland, 2009.

17. Chen HY, Ge Z, Wu YJ, Wu LY, Sun M, Tian T, Qiou HR, Liu P and Li JY: Immunophenotypic analysis of Philadelphia chromosome positive acute lymphoblastic leukaemia in adults. Zhongguo Shi Yan Xue Ye Xue Za Zhi 18: 714-717, 2010 (In Chinese).

18. Miao Y, Fan L, Wu YJ, Xia Y, Qiao C, Wang Y, Wang L, Hong M, Zhu HY, Xu W and Li JY: Low expression of CD200 predicts shorter time-to-treatment in chronic lymphocytic leukemia. Oncotarget 7: 13551-13562, 2016

19. Van Vlierberghe P, Palomero T, Khiabanian H, Van der Meulen J, Castillo M, Van Roy N, De Moerloose B, Philippé J, González-García S, Toribio ML, et al: PHF6 mutations in T-cell acute lymphoblastic leukemia. Nat Genet 42: 338-342, 2010.

20. Ferguson SM and De Camilli P: Dynamin, a membrane-remodelling GTPase. Nat Rev Mol Cell Biol 13: 75-88, 2012.

21. Bitoun M, Maugenre S, Jeannet PY, Lacène E, Ferrer X, Laforêt $P$, Martin JJ, Laporte J, Lochmüller H, Beggs AH, et al: Mutations in dynamin 2 cause dominant centronuclear myopathy. Nat Genet 37: 1207-1209, 2005.

22. Aidaralieva NJ, Kamino K, Kimura R, Yamamoto M, Morihara T, Kazui H, Hashimoto R, Tanaka T, Kudo T, Kida T, et al: Dynamin 2 gene is a novel susceptibility gene for late-onset Alzheimer disease in non-APOE-epsilon4 carriers. J Hum Genet 53: 296-302, 2008

23. Koutsopoulos OS, Kretz C, Weller CM, Roux A, Mojzisova H, Böhm J, Koch C, Toussaint A, Heckel E, Stemkens D, et al: Dynamin 2 homozygous mutation in humans with a lethal congenital syndrome. Eur J Hum Genet 21: 637-642, 2013.

24. Nagai K, Kohno T, Chen YX, Tsushima H, Mori H, Nakamura H, Jinnai I, Matsuo T, Kuriyama K, Tomonaga M and Bennett JM. Diagnostic criteria for hypocellular acute leukemia: A clinical entity distinct from overt acute leukemia and myelodysplastic syndrome. Leuk Res 20: 563-574, 1996.

25. Hu X, Fu W, Wang L, Gao L, Lü S, Xi H, Qiu H, Chen L, Chen J, Ni X, et al: HAG regimen improves survival in adult patients with hypocellular acute myeloid leukemia. Oncotarget 7: 3623-3634, 2016.

26. Chamary JV, Parmley JL and Hurst LD: Hearing silence: Non-neutral evolution at synonymous sites in mammals. Nat Rev Genet 7: 98-108, 2006.

27. Goymer P: Synonymous mutations break their silence. Nat Rev Genet 8: 92, 2007.

28. Zhou T, Ko EA, Gu W, Lim I, Bang H and Ko JH: Non-silent story on synonymous sites in voltage-gated ion channel genes. PLoS One 7: e48541, 2012. 